\title{
Minimally Invasive Approach in Surgical Management of Renal Neoplasms National Cancer Institute Experience
}

\author{
Amr Mounir Selim ${ }^{1 *}$, Ashraf Saad Zaghloul ${ }^{1}$, Hatem Ahmed AbouLkassem¹, Amr Farouk Fergany ${ }^{2,3}$, Abdelmaksoud Mohamed \\ Abdelmaksoud1, Waleed Mohamed Fadlalla ${ }^{1}$, Mahmoud Amr Abd Elhakim ${ }^{4}$, Rasha Mahmoud Allam ${ }^{5}$ \\ ${ }^{1}$ Department of Surgical Oncology, National Cancer Institute, Cairo University, Cairo, Egypt; ${ }^{2}$ Department of Urologic \\ Oncology, Section of Laparoscopy and Robotics, Cleveland Clinic, Cleveland, Ohio, USA; ${ }^{3}$ Department of Urologic Oncology, \\ National Cancer Institute, Cairo University, Cairo, Egypt; ${ }^{4}$ Department of Urology, Kasr Alainy Faculty of Medicine, Cairo \\ University, Cairo, Egypt; ${ }^{5}$ Department of Biostatistics \& Cancer Epidemiology, National Cancer Institute, Cairo University, \\ Cairo, Egypt
}

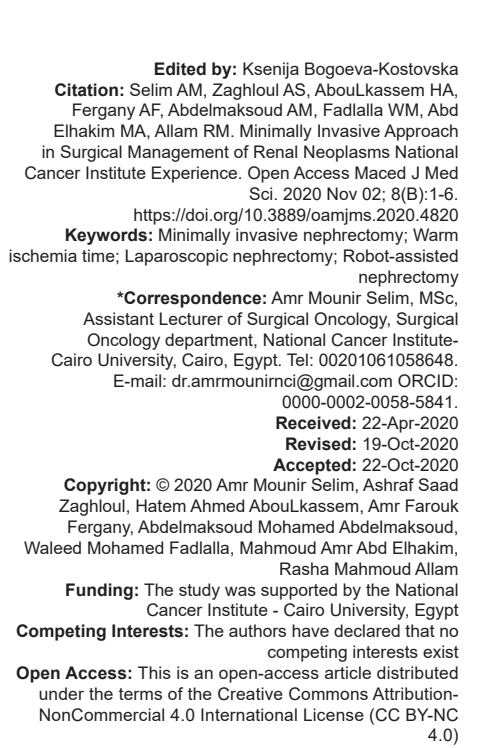

Abstract

BACKGROUND: Minimally invasive nephrectomy is considered a technically challenging procedure requiring a long learning curve to reach acceptable warm ischemia time and perioperative complications. These minimally invasive techniques result in a shorter hospital stay and less post-operative pain.

AIM: This study aims to demonstrate the National Cancer Institute experience regarding the benefits of laparoscopic and robot-assisted nephrectomy over open technique.

METHODS: This is a retrospective descriptive cohort study including 62 patients with renal masses treated with nephrectomy whether partial, total or radical, 26 cases were treated by minimally invasive techniques ( 8 robotic and 18 laparoscopic), while 36 cases were treated by open technique. Inclusion criteria were patients between 20 and 70 years with renal neoplasm without renal vein thrombosis, with tumor stage T1 or T2 N0 M0. Exclusion criteria were patients with medical comorbidities that preclude surgical management or minimally invasive techniques and patients refusing surgery in general.

RESULTS: Minimally invasive nephrectomy resulted in shorter hospital stay (mean hospital stay was 2.2 days for the minimally invasive group and 3.6 days for the open group) and less post-operative pain than open technique $(p<0.001$ and $=0.002$, respectively), while open technique resulted in shorter operation time $(p=0.039$, mean operation time 147.8 min compared to 184.8 in the minimally invasive group).

CONCLUSION: Minimally invasive nephrectomy (laparoscopic and robotic) resulted in less post-operative pain and shorter hospital stay compared to open technique despite consuming longer operation time which may be decreased by improving the learning curve of operating surgeons.

\section{Introduction}

Renal cell carcinoma (RCC) represents $2 \%$ of adult malignancies. However, it is the most common malignancy arising in the renal parenchyma [1]. After prostate and bladder cancer, it is the third most common urologic tumor. In the United States, there are approximately 74,000 new cases and almost 15,000 deaths from RCC each year [2].

Laparoscopy and robot-assisted surgery have intervened in all aspects of renal surgery. There is a growing trend to perform fewer and fewer open surgeries on the kidney for renal masses. Furthermore, these minimally invasive techniques are better tolerated by patients, with a shorter hospital stay, and earlier return to normal activity [3].

\section{Objective}

This study aims to demonstrate the National Cancer Institute $(\mathrm{NCl})$ experience regarding benefits of laparoscopic and robot-assisted nephrectomy over open technique.

\section{Patients and Methods}

This was a retrospective cohort study which included patients presented to the urology unit at $\mathrm{NCl}$; Cairo University with renal tumors (benign or malignant).

The patients were divided into two groups, minimally invasive group including 26 patients (8 robotic 
and 18 laparoscopic) and open group including 36 patients. Analysis of patients was done by intention to treat analysis. Patients who were converted from minimally invasive techniques to open technique were included in the minimally invasive techniques group. These cases were treated by surgical intervention between March 2015 and August 2018.

Inclusion criteria were patients between 20 and 70 years with renal neoplasm (benign or malignant) detected by computed tomography (CT) abdomen and pelvis with contrast without renal vein thrombosis, with tumor stage T1 or T2 NO M0.

Exclusion criteria were patients with medical comorbidities that preclude surgical management or minimally invasive techniques and patients refusing surgery in general.

Patients were diagnosed by history taking and clinical examination in the outpatient clinic and by investigations including laboratory tests (complete blood count, liver function tests, kidney function tests, and coagulation profile) and radiological imaging (CT of abdomen and pelvis with contrast, chest X-ray or CT chest if clinically indicated, with or without bone scan according to symptoms of bone pains or elevated alkaline phosphatase).

\section{Table 1: Fuhrman grading system}

\begin{tabular}{ll}
\hline Grade & Description \\
\hline 1 & $\begin{array}{l}\text { Tumors were composed of cells with small }(\sim 10 \mu \mathrm{m}) \text { round uniform nuclei with } \\
\text { inconspicuous or absent nucleoli }\end{array}$ \\
2 & $\begin{array}{l}\text { Tumor cells had larger }(\sim 15 \mu \mathrm{m}) \text { nuclei that exhibited irregularities in the outline } \\
\text { and nucleoli when examined under high-power magnification }(\times 400)\end{array}$ \\
3 & $\begin{array}{l}\text { Tumor cells had even larger nuclei }(\sim 20 \mu \mathrm{m}) \text { with an obviously irregular outline } \\
\text { and prominent large nucleoli even at low-power magnification }(\times 100)\end{array}$ \\
4 & $\begin{array}{l}\text { Tumor cells exhibit characteristics similar to those of grade } 3 \text { tumors with the } \\
\text { addition of bizarre, often multilobed nuclei, and heavy chromatin clumps. These } \\
\text { tumors often display areas of spindled-shaped cells resembling sarcomas }\end{array}$ \\
\hline
\end{tabular}

Tumor size was measured as the longest diameter of each tumor in any single plane of the preoperative imaging study. Histological subtyping and pathologic staging were performed according to the $7^{\text {th }}$ edition of American Joint Committee guidelines and cellular grading was performed by the Fuhrman's grading system [4], [5] (Table 1).

Table 2: Clavien-Dindo system

\begin{tabular}{|c|c|}
\hline Grade & Definition \\
\hline Grade I & $\begin{array}{l}\text { Any deviation from the normal post-operative course without the need } \\
\text { for pharmacological treatment or surgical, endoscopic, and radiological } \\
\text { interventions } \\
\text { Allowed therapeutic regimens are: Drugs as antiemetics, antipyretics, } \\
\text { analgesics, diuretics, electrolytes, and physiotherapy. This grade also } \\
\text { includes wound infections opened at the bedside }\end{array}$ \\
\hline Grade II & $\begin{array}{l}\text { Requiring pharmacological treatment with drugs other than such allowed for } \\
\text { grade I complications } \\
\text { Blood transfusions and total parenteral nutrition are also included }\end{array}$ \\
\hline Grade III & Requiring surgical, endoscopic, or radiological intervention \\
\hline Grade IIla & Intervention not under general anesthesia \\
\hline Grade IIIb & Intervention under general anesthesia \\
\hline Grade IV & $\begin{array}{l}\text { Life-threatening complication (including CNS complications) requiring } \\
\text { intermediate care/intensive care unit management }\end{array}$ \\
\hline Grade IVa & Single organ dysfunction (including dialysis) \\
\hline Grade IVb & Multiorgan dysfunction \\
\hline Grade V & Death of a patient \\
\hline Suffix "d" & $\begin{array}{l}\text { If the patient suffers from a complication at the time of discharge (see } \\
\text { examples in Table 2), the suffix "d" (for "disability") is added to the respective } \\
\text { grade of complication. This label indicates the need for a follow-up to fully } \\
\text { evaluate the complication }\end{array}$ \\
\hline
\end{tabular}

Parameters of evaluation to compare minimally invasive techniques versus open technique included T N M staging, operative factors for both techniques (intraoperative complications, operation time, estimated blood loss, blood transfusion, rate of conversion to open technique), post-operative factors in relation to both procedures (hospital stay, post-operative pain, post-operative complications as bleeding, wound infection, and urine leak), and oncologic safety of the procedure regarding safety margin. Post-operative pain was assessed by pain score (mild, moderate and severe). The early postoperative complications (within 30 days after surgery) were evaluated by central review of medical records for every case included and classified using the Clavien-Dindo system [6] (Table 2).

\section{Statistical analysis}

Data were analyzed using IBM SPSS advanced statistics (Statistical Package for Social Sciences), version 24 (SPSS Inc., Chicago, IL). Numerical data were described as median and range or mean and standard deviation as appropriate, while qualitative data were described as frequency and percentage. Chi-square (Fisher's exact) test was used to examine the relation between qualitative variables as appropriate.

A $p \leq 0.05$ was considered statistically significant. All tests were two-tailed.

\section{Results}

The clinical and pathological characteristics of all patients are summarized in Table 3.

The mean age was $45 \pm 13.4$ years for the minimally invasive group and $49 \pm 11.9$ years for the open group, as shown in Figure 1.

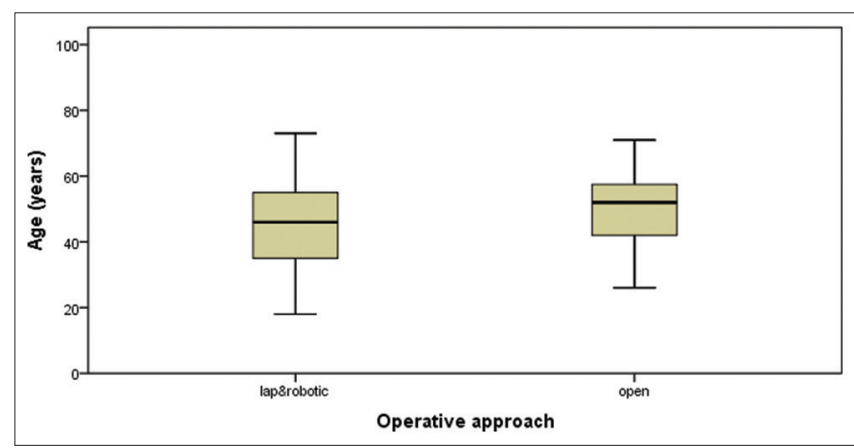

Figure 1: Patients' characteristics regarding age

Sixty cases were diagnosed by CT, while 2 cases by magnetic resonance imaging. Twenty-eight cases had clear cell RCC, 11 cases had papillary 
RCC, 12 cases had chromophobe RCC, and 11 cases had other types of pathology. There was no statistical significance regarding pathological staging $(p=0.193)$ and cellular grading $(p=1)$ between the two groups, as shown in Table 3.

Mean operation time was $147.8 \mathrm{~min}$ in the open group compared to 184.8 in the minimally invasive group, as shown in Table 4 and Figure 3. Operation time

Table 3: Comparison between minimally invasive (laparoscopic and robotic) and open nephrectomy regarding clinicopathological characteristics of the entire patients

\begin{tabular}{|c|c|c|c|c|}
\hline \multirow[t]{2}{*}{ Characteristics } & \multicolumn{2}{|l|}{ Operation approach } & \multirow[t]{2}{*}{ Total } & \multirow[t]{2}{*}{$\mathrm{p}$-value } \\
\hline & Lap and robotic $(n=26)$ & Open $(n=36)$ & & \\
\hline \multicolumn{5}{|c|}{ Post-operative pain } \\
\hline \multicolumn{5}{|l|}{ No } \\
\hline No & 10 & 2 & 12 & \multirow{5}{*}{0.001} \\
\hline$\%$ & $38.5 \%$ & $5.6 \%$ & $19.4 \%$ & \\
\hline \multicolumn{4}{|l|}{ Yes } & \\
\hline No & 16 & 34 & \multirow{2}{*}{$\begin{array}{l}50 \\
80.6 \%\end{array}$} & \\
\hline$\%$ & $61.5 \%$ & $94.4 \%$ & & \\
\hline \multicolumn{5}{|l|}{ Gender } \\
\hline Female & & & & \\
\hline No & 17 & 16 & 33 & \multirow[t]{5}{*}{0.103} \\
\hline$\%$ & $65.4 \%$ & $44.4 \%$ & $53.2 \%$ & \\
\hline \multirow{4}{*}{\multicolumn{5}{|c|}{$\begin{array}{ll}\begin{array}{ll}\text { Male } \\
\quad \text { No } \\
\%\end{array} & 9 \\
\text { Need for blood transfusion } & \end{array}$}} \\
\hline & & & & \\
\hline & & & & \\
\hline & & & & \\
\hline \multicolumn{5}{|l|}{ Not needed } \\
\hline No & 23 & 33 & 56 & \multirow[t]{5}{*}{0.689} \\
\hline$\%$ & $88.5 \%$ & $91.7 \%$ & $90.3 \%$ & \\
\hline \multirow{5}{*}{\multicolumn{5}{|c|}{$\begin{array}{l}\text { Needed } \\
\text { No } \\
\% \\
\text { Pain degree }(n=50) \\
\text { Mild }\end{array}$}} \\
\hline & & & & \\
\hline & & & & \\
\hline & & & & \\
\hline & & & & \\
\hline No & $15 \mathrm{a}$ & $14_{b}$ & 29 & \multirow[t]{5}{*}{0.002} \\
\hline$\%$ & $93.8 \%$ & $41.2 \%$ & $58.0 \%$ & \\
\hline \multirow{4}{*}{\multicolumn{5}{|c|}{$\begin{array}{l}\text { Moderate } \\
\text { No } \\
\% \\
\text { Severe }\end{array}$}} \\
\hline & & & & \\
\hline & & & & \\
\hline & & & & \\
\hline No & 0 & 6 & 6 & \\
\hline$\%$ & $0.0 \%$ & $17.6 \%$ & $12.0 \%$ & \\
\hline Tumor size $(\mathrm{cm})$ & & & & \\
\hline$<6$ & & & & \\
\hline No & 13 & 14 & 27 & 0.357 \\
\hline$\%$ & $52 \%$ & $40 \%$ & $45 \%$ & \\
\hline$\geq 6$ & & & & \\
\hline No & 12 & 21 & 33 & \\
\hline$\%$ & $48 \%$ & $60 \%$ & $55 \%$ & \\
\hline Pathological sta & & & & \\
\hline PT1a & & & & \\
\hline No & 7 & 7 & 14 & 0.193 \\
\hline$\%$ & $26.9 \%$ & $19.4 \%$ & $22.6 \%$ & \\
\hline PT1b & & & & \\
\hline No & 13 & 11 & 24 & \\
\hline$\%$ & $50 \%$ & $30.6 \%$ & $38.7 \%$ & \\
\hline PT2a & & & & \\
\hline No & 4 & 11 & 15 & \\
\hline$\%$ & $15.4 \%$ & $30.6 \%$ & $24.2 \%$ & \\
\hline $\mathrm{T} 2 \mathrm{bP}$ & & & & \\
\hline No & 2 & 7 & 9 & \\
\hline$\%$ & $7.7 \%$ & $19.4 \%$ & $14.5 \%$ & \\
\hline Cellular grading & & & & \\
\hline Grade 1 and 2 & & & & \\
\hline No & 21 & 27 & 48 & 1.000 \\
\hline$\%$ & $91.3 \%$ & $90 \%$ & $91 \%$ & \\
\hline Grade 3 and 4 & & & & \\
\hline No & 2 & 3 & 5 & \\
\hline$\%$ & $8.7 \%$ & $10 \%$ & $9 \%$ & \\
\hline
\end{tabular}

was shorter in open technique. This was statistically significant $(p=0.039)$.

Mean blood loss during minimally invasive nephrectomy was $383.7 \mathrm{ml}$ compared to $463.3 \mathrm{ml}$ during open technique, but the results were not statistically significant $(p=0.677)$. Mean hospital stay was 2.2 days for the minimally invasive group and 3.6 days for the open group which was statistically significant $(p<0.001)$, as shown in Table 4.

Open partial nephrectomy (OPN) was converted to radical in 3 cases (due to iatrogenic injury of the left ureter, 1 ; bleeding from the left renal vein, 1; and bleeding from operative renal bed, 1). Duodenal tear occurred in 1 case in the open group which was treated by primary repair. Laparoscopic nephrectomy was converted to open technique in 6 cases (due to technical difficulty, 2; renal vein bleeding, 1; operative bed bleeding, 2; gonadal vein bleeding, 1). Cases with open conversions were included in the analysis of perioperative complications, as a part of the laparoscopic group with grade IIIb complications.

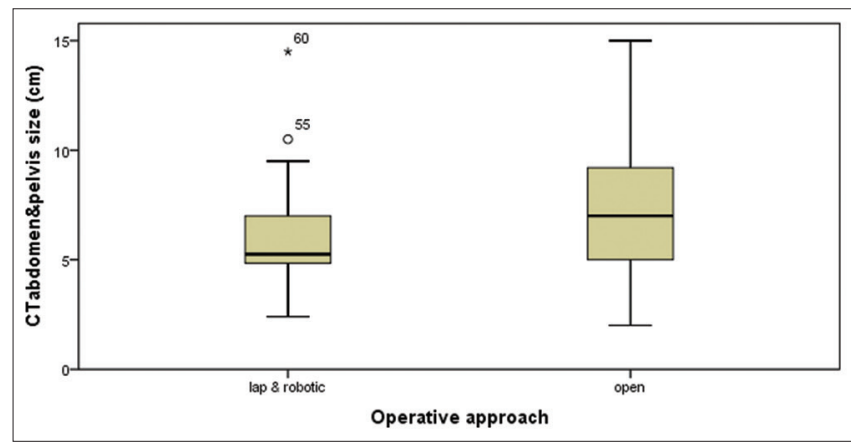

Figure 2: Comparison between minimally invasive (laparoscopic and robotic) and open nephrectomy regarding tumor size

Half of the cases done by minimally invasive technique were located in the lower zone while half of the cases done by open technique were located in the upper zone which was statistically significant $(p=0.007)$. In the laparoscopic group, 4 patients underwent partial nephrectomy, 11 patients underwent total nephrectomy, and 3 patients underwent radical nephrectomy, while in robotic group, 7 patients underwent partial nephrectomy and 1 patient underwent total nephrectomy (Figure 2).

Three patients had positive margin after resection ( 2 open partial and 1 laparoscopic partial nephrectomies).

Table 4: Comparison between minimally invasive (laparoscopic and robotic) and open nephrectomy regarding age, tumor size, operative time, blood loss, and hospital stay

\begin{tabular}{|c|c|c|c|c|c|c|c|c|c|c|c|}
\hline \multirow[t]{2}{*}{ Operative approach } & \multicolumn{5}{|c|}{ Lap and robotic $(n=26)$} & \multicolumn{5}{|c|}{ Open $(n=36)$} & \multirow[t]{2}{*}{$p$-value } \\
\hline & Median & Minimum & Maximum & Mean & SD & Median & Minimum & Maximum & Mean & SD & \\
\hline Age (years) & 46.0 & 18 & 73 & 45.2 & 13.4 & 52.0 & 26 & 71 & 49.4 & 11.9 & 0.204 \\
\hline Tumor size $(\mathrm{cm})$ & 5.5 & 2.4 & 14.5 & 6.3 & 2.6 & 7 & 2 & 15 & 7.44 & 3.5 & 0.170 \\
\hline Operation time (min) & 180.0 & 75 & 420 & 184.8 & 67.0 & 152.5 & 45 & 230 & 147.8 & 42.1 & 0.010 \\
\hline Blood loss & 350.0 & 50 & 1200 & 383.7 & 291.1 & 300.0 & 50 & 2500 & 463.3 & 502.4 & 0.886 \\
\hline WIT (min) & 20 & 15 & 35 & 23.45 & 6.039 & 22 & 8 & 29 & 20.84 & 6.362 & 0.279 \\
\hline Hospital stay (days) & 2.0 & 2.0 & 3.0 & 2.2 & 0.4 & 3.0 & 2.00 & 7.00 & 3.6 & 1.1 & $<0.001$ \\
\hline
\end{tabular}

WIT: Warm ischemia time 


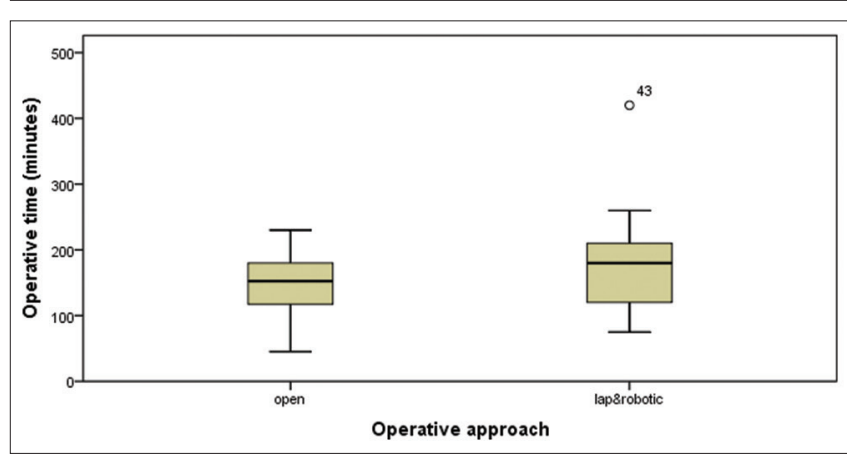

Figure 3: Comparison between minimally invasive (laparoscopic and robotic) and open nephrectomy regarding operation time

Ten patients $(38.5 \%)$ in the minimally invasive group and 2 patients (5.6\%) in the open group did not experience any post-operative pain. Robotic technique was associated with the least post-operative pain which was statistically significant $(p=0.001)$, as shown in Table 5.

Fifteen patients in the minimally invasive group and 14 patients in the open group experienced mild post-operative pain which was statistically significant $(p=0.002)$, as shown in Table 3.

Table 5: Comparison between laparoscopic and robotic nephrectomy regarding post-operative pain $(n=26)$

\begin{tabular}{clll}
\hline Post-operative pain presence & \multicolumn{2}{l}{ Operation approach } & p-value \\
\cline { 2 - 3 } & Lap & robotic & \\
\hline No & & & \\
No & 3 & 7 & 0.001 \\
$\%$ & $16.7 \%$ & $87.5 \%$ & \\
Yes & 15 & 1 & \\
No & 15 & $12.5 \%$ & \\
$\%$ & $83.3 \%$ & & \\
\hline
\end{tabular}

Regarding post-operative complications, 1 patient developed urine leak post-operative after OPN which was treated by image-guided aspiration. Only 1 patient developed wound infection at specimen extraction site after laparoscopic total nephrectomy which was managed by wound culture, antibiotic and frequent dressing. 1 patient developed port site hernia after robotic partial nephrectomy (RPN) which was treated by mesh hernioplasty.

Furthermore, we compared post-operative complication rates between the minimally invasive and open groups and the complication rates were not significantly different between the two groups $(p=0.147$, as shown in Table 6$)$.

\section{Discussion}

In this study, minimally invasive nephrectomy resulted in a shorter hospital stay and less postoperative pain than open technique which was statistically significant, while open technique resulted in shorter operation time which was statistically significant. Another study including 106 patients who underwent
Table 6: Comparison between minimally invasive (laparoscopic and robotic) and open nephrectomy regarding intraoperative and post-operative complications

\begin{tabular}{|c|c|c|c|c|}
\hline \multirow[t]{2}{*}{ Complications } & \multicolumn{2}{|l|}{ Operation approach } & \multirow[t]{2}{*}{ Total } & \multirow[t]{2}{*}{ p-value } \\
\hline & Laparoscopic and robotic & Open & & \\
\hline \multirow{2}{*}{\multicolumn{5}{|c|}{$\begin{array}{c}\text { Clavien-Dindo classification } \\
\text { | }\end{array}$}} \\
\hline & & & & \\
\hline No & 1 & 0 & 1 & \\
\hline$\%$ & $3.8 \%$ & $0.0 \%$ & $1.6 \%$ & 0.147 \\
\hline \multicolumn{5}{|l|}{ IIla } \\
\hline No & 0 & 1 & 1 & \\
\hline$\%$ & $0.0 \%$ & $2.8 \%$ & $1.6 \%$ & \\
\hline \multicolumn{5}{|l|}{ Illb } \\
\hline No & 7 & 4 & 11 & \\
\hline$\%$ & $26.9 \%$ & $11.1 \%$ & $17.7 \%$ & \\
\hline \multicolumn{5}{|c|}{ No complication } \\
\hline No & 18 & 31 & 49 & \\
\hline$\%$ & $69.2 \%$ & $86.1 \%$ & $79.0 \%$ & \\
\hline \multicolumn{5}{|l|}{ Total } \\
\hline No & 26 & 36 & 62 & \\
\hline$\%$ & $100.0 \%$ & $100.0 \%$ & $100.0 \%$ & \\
\hline
\end{tabular}

open, laparoscopic and RPN concluded that RPN offers less blood loss, fewer post-operative complications, and overcomes the technical difficulties of laparoscopic partial nephrectomy (LPN) [7].

Another study including 96 partial nephrectomy patients (54 open, 15 laparoscopic, and 27 robotic) showed that OPN had advantages in operative time and ischemia time, at the expense of increased blood loss, which was, in part, due to differences in operative technique [8].

A separate large series of OPN reported a shorter operation time (155 $\pm 59 \mathrm{~min})$, but similar ischemia time $(20.1 \pm 10.9 \mathrm{~min})$ and blood loss (median $=350 \mathrm{~mL})$. A higher $(15.3 \%)$ transfusion rate was reported [9].

While comparison of RPN to OPN is limited in the literature, there are several studies that compare LPN to OPN. The largest comparison (771 LPN vs. 1,028 OPN) also shows reduced warm ischemia time for OPN versus LPN (30.7 min vs. $20.1 \mathrm{~min}$ ), positive margins (2.85\% LPN vs. $1.6 \%$ OPN), and blood loss was similar for OPN and LPN ( $300 \mathrm{~mL}$ vs. $376 \mathrm{~mL})$ with a $5 \%$ transfusion rate for both groups [10].

A systematic review and meta-analysis done by Liu et al. were published in 2017 comparing laparoscopic radical nephrectomy (LRN) and open radical nephrectomy (ORN) regarding operation time, blood loss, intraoperative complications, hospital stay, time to start oral intake, post-operative complications, and overall mortality. This review included 37 studies, data were available from 14,515 RCC patients, of whom 4844 used LRN and 9671 used ORN for treatment of RCC. Data on intraoperative complications were available for analysis in 695 patients in LRN group with 64 events and 559 patients in ORN group with 48 events. The pooled analysis showed that there was no significant difference in intraoperative complications between LRN group and ORN group. Subgroup analyses showed that LRN group had a significantly higher risk of intraoperative complications than ORN group in patients with mean tumor size smaller than $7 \mathrm{~cm}$ [11]. This was similar to our study which showed 
that intraoperative complications were more in the laparoscopic group due to lack of surgeons' experience.

In addition, this meta-analysis showed that LRN has been shown to offer superior perioperative results to ORN, including shorter hospital stay, time to start oral intake, and convalescence time, and less estimated blood loss, blood transfusion rate, and anesthetic consumptions but longer operation time [11]. Similarly, our study showed that laparoscopic nephrectomy resulted in longer operation time, less blood loss, shorter hospital stay, less post-operative pain, and shorter time to oral intake than the open technique.

A recent retrospective study done by Lee et al. was published in 2018 comparing oncological outcomes and perioperative complications between laparoscopic and open radical nephrectomies in patients with clinical T2 RCC. This study including 964 patients (578 in the open group and 257 in the laparoscopic group) showed that LRN was converted to ORN in 13 cases (because of severe bleeding, 6; other organ damage, 3; and technical difficulty, 4). Furthermore, intraoperative complication rates were not significantly different between the laparoscopic and open groups. This study is the largest among the studies that compared oncological outcomes between ORN and LRN that had a relatively long follow-up period [12]. In our study, 7 patients who were planned for laparoscopic nephrectomy were converted to open technique (2 technical difficulties and 5 bleeding). Similarly, in our study, intraoperative complication rates were not significantly different between the laparoscopic and open groups. In our study, 23 patients had T2 renal masses $\geq 7 \mathrm{~cm}$ ( 7 cases were done laparoscopic and 16 cases done by open technique).

Steinberg et al. compared the post-operative outcomes of LRN and those of ORN and found that clinical T2 renal masses can be efficiently managed using the laparoscopic approach, with additional advantages of a shorter hospital stay, decreased blood loss, and more rapid recovery than ORN [13]. Similarly, our study showed that laparoscopic nephrectomy resulted in less blood loss, shorter hospital stay, less post-operative pain, and shorter time to oral intake than open technique.

In another study, Hemal et al. also compared post-operative outcomes between LRN and ORN in patients with clinical T2 renal tumors but with a longer follow-up period. They found that the LRN group had superior post-operative outcomes in terms of less blood loss, shorter hospital stay decreased analgesic requirement, and more rapid convalescence even though the LRN group required a longer operation time than the ORN group (180.8 vs. $165.3 \mathrm{~min}$, $p=0.029$ ) [14]. Similarly, our study showed that laparoscopic nephrectomy resulted in longer operation time, less blood loss, shorter hospital stay, less postoperative pain, and shorter time to oral intake than open technique.
In a prospective observational comparative study published in 2018 analyzing laparoscopic versus ORN for renal tumors more than $7 \mathrm{~cm}$, thirty patients were included in each ORN and LRN group [15]. In this study, blood loss was more in patients who underwent ORN as compared to those who underwent LRN which was similar to our study. Furthermore, LRN was associated with longer operation time than ORN (187.5 \pm 48.49 vs. $163.6 \pm 46.35$ ) which was similar to our study which may be due to surgeons' experience which needs to be improved by acquiring more skills and improving learning curve in laparoscopic technique. Longer operation time is associated with slow post-operative recovery due to prolonged anesthesia, but the benefit of less blood loss and less pain usually compensates for better recovery in LRN group despite longer operative times [15].

Furthermore, in this study, mean hospital stay was 6.1 days (range 4-11 days) for patients who underwent ORN and 4.2 days (range 3-8 days) for patients who underwent LRN [15]. Similarly, our study revealed that LRN resulted in shorter hospital stay than ORN which is due to minimal handling of tissues, less post-operative pain, and early oral intake.

The common intraoperative complication in ORN/LRN is vascular injury and bowel injury. In this study done by Khan et al., intraoperative complication rate was similar in ORN and LRN groups. In the ORN group, one patient had inferior vena cava injury due to avulsion of the gonadal vein. One patient in the ORN group had bowel injury (colonic serosal tear). In the LRN group, one patient had bowel injury and one patient had hemorrhage due to clip dislodgement from renal vein [15]. Similarly, in our study, intraoperative complication rates were not significantly different between the laparoscopic and open groups. Laparoscopic nephrectomy was converted to open technique in 6 cases (due to technical difficulty, 2; renal vein bleeding, 1; operative bed bleeding, 2; and gonadal vein bleeding, 1 ).

\section{Conclusion}

Minimally invasive nephrectomy (laparoscopic and robotic) resulted in less post-operative pain and shorter hospital stay compared to open technique despite consuming longer operation time which may be decreased by improving the learning curve of operating surgeons.

\section{Compliance with Ethical Standards}

The study was approved by the ethical committee of $\mathrm{NCl}$. Clinical data were collected from 
hospital medical records and investigations' reports, recorded in a standard database form, evaluated, and analyzed by the authors. For this type of study (retrospective study), formal consent is not required.

\section{References}

1. Jemal A, Siegel R, Ward E, Murray T, Xu J, Smigal C, et al. Cancer statistics, 2006. CA Cancer J Clin. 2006;56(2):106-30. https://doi.org/10.3322/canjclin.56.2.106 PMid:16514137

2. SiegelRL, Miller KD, Jemal A. Cancer Statistics, 2019. CACancer J Clin. 2019;69(1):7-34. https://doi.org/10.3322/caac.21551 PMid:30620402

3. Campbell SC, Novick AC, Belldegrun A, Blute ML, Chow GK, Derweesh $\mathrm{IH}$, et al. Guideline for management of the clinical T1 renal mass. J Urol. 2009;182(4):12719. PMid:19683266 https://doi.org/10.1016/j.juro.2009.07.004

4. Edge SB, Compton CC. The American joint committee on cancer: The $7^{\text {th }}$ edition of the AJCC cancer staging manual and the future of TNM. Ann Surg Oncol. 2010;17(6):14714. https://doi.org/10.1245/s10434-010-0985-4 PMid:20180029

5. Fuhrman SA, Lasky LC, Limas C. Prognostic significance of morphologic parameters in renal cell carcinoma. Am J Surg Pathol. 1982;6(7):655-63. https://doi.org/10.1097/00000478-198210000-00007 PMid:7180965

6. Clavien PA, Barkun J, de Oliveira ML, Vauthey JN, Dindo D, Schulick RD, et al. The Clavien-Dindo classification of surgical complications: Five-yearexperience.Ann Surg. 2009;250(2):18796. https://doi.org/10.1097/sla.0b013e3181b13ca2 PMid:19638912

7. Klaassen Z, Kohut RM Jr., Patel D, Terris MK, Madi R. A single surgeon's experience with open, laparoscopic, and robotic partial nephrectomy. Int Sch Res Notices. 2014;2014:430914. https://doi.org/10.1155/2014/430914
8. Lucas SM, Mellon MJ, Erntsberger L, Sundaram CP. A comparison of robotic, laparoscopic and open partial nephrectomy. JSLS. 2012;16(4):581-7. https://doi.org/10.4293/108680812x13462882737177 PMid:23484568

9. Patard JJ, Pantuck AJ, Crepel M, Lam JS, Bellec L, Albouy B, et al. Morbidity and clinical outcome of nephron-sparing surgery in relation to tumour size and indication. Eur Urol J. 2007;52(1):14854. PMid:17240036

10. Gill IS, Kavoussi LR, Lane BR, Blute ML, Babineau D, Colombo JR Jr., et al. Comparison of 1,800 laparoscopic and open partial nephrectomies for single renal tumors. J Urol. 2007;178(1):41-6. ｈttps://doi.org/10.1016/j.juro.2007.03.038 PMid:17574056

11. Liu G, Ma Y, Wang S, Han X, Dianjun G. Laparoscopic versus open radical nephrectomy for renal cell carcinoma: A systematic review and meta-analysis. Transl Oncol. 2017;10(4):50110. PMid:28550770

12. Lee $\mathrm{H}$, Lee $\mathrm{CU}$, Yoo JH, Sung $\mathrm{HH}$, Jeong BC, Jeon SS, et al. Comparisons of oncological outcomes and perioperative complications between laparoscopic and open radical nephrectomies in patients with clinical T2 renal cell carcinoma ( $\geq 7 \mathrm{~cm})$. PLoS One. 2018;13(1):e0191786. https://doi.org/10.1371/journal.pone.0191786 PMid:29364958

13. Steinberg AP, Finelli A, Desai MM, Abreu SC, Ramani AP, Spaliviero $\mathrm{M}$, et al. Laparoscopic radical nephrectomy for large (greater than $7 \mathrm{~cm}$, T2) renal tumors. J Urol. 2004;172:21726. https://doi.org/10.1097/01.ju.0000140961.53335.04 PMid:15538225

14. Hemal AK, Kumar A, Kumar R, Wadhwa P, Seth A, Gupta NP. Laparoscopic versus open radical nephrectomy for large renal tumors: A long-term prospective comparison. J Urol. 2007;177(3):862-6. https://doi.org/10.1016/j.juro.2006.10.053 PMid:17296361

15. Ali Khan MM, Patel RA, Jain N, Balakrishnan A, Venkataraman M. Prospective analysis of laparoscopic versus open radical nephrectomy for renal tumours more than $7 \mathrm{~cm}$. J Minim Access Surg. 2018;15(1):148. PMid:29582796 